\title{
Chemical corrosion of external stairs - case study
}

\author{
Przemysław Czapik ${ }^{1, *}$, and Zdzisława Owsiak ${ }^{1}$ \\ ${ }^{1}$ Department of Building Engineering Technologies and Organization, Kielce University of \\ Technology, Al. Tysiąclecia Państwa Polskiego 7, 25-314 Kielce, Poland
}

\begin{abstract}
On the basis of examinations of the efflorescences formed on the concrete surface, an attempt was made to analyze the sources of concrete corrosion without entering inside the construction. The concrete stairs revealed the symptoms of leaching, as a result of alkali-aggregate reactions developing beneath the surface. As a result of this corrosion process and the carbonation propagating from the concrete surface, the carbonate efflorescences were found. Their phase composition was determined by X-ray diffraction. In order to identify whether the efflorescences were the results of the alkali-silica reaction or alkalicarbonate reaction, the microstructure was investigated using the scanning electron microscope together with energy dispersive spectroscopy.
\end{abstract}

\section{Introduction}

The construction of the concrete entrance stairs to the public utility building built between 2009 and 2013 is the object of the research reported in this work. The stairs were built of concrete containing dolomite aggregate and quartz sand. Granite tiles were laid on the stairs and stair risers, while the side walls of the structure were painted with the paint for concrete. After several years, numerous deposits of efflorescence appeared on the side walls of the stairway structure in the form of massive, layered encrustations (Fig. $1 \mathrm{a}$ and b) or, appearing near cracks, caused severe surface scaling (Fig. 1c). The observed phenomena are a proof of concrete corrosion [1-5]. To identify the corrosion type, the samples from the eroded surface were collected for examination, without disturbing the structure of stairs [1, 6]. The phase composition and microstructure of samples were investigated.

\footnotetext{
*Corresponding author: p.czapik@tu.kielce.pl
} 


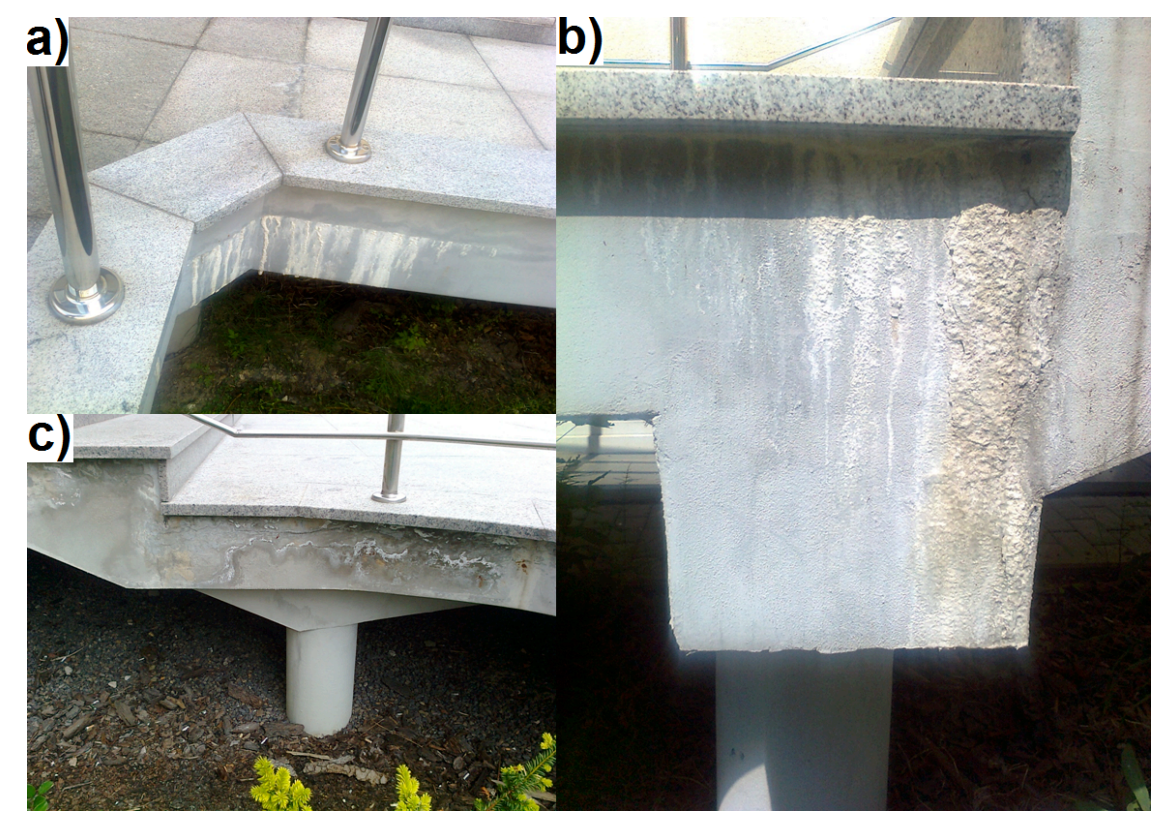

Fig. 1. a), b) Layered massive encrustations on the side surfaces of stair structures, c) surface scaling near horizontal cracks.

\section{Materials and Methods}

The samples taken from the massive encrustations shown in Fig. 1a) and b) were designated as samples A and B, respectively, and samples taken from the flakes formed around the cracks were designated as $\mathrm{C}$, (Fig. 1c). The collected material was ground to the grain size below $0.063 \mathrm{~mm}$ and averaged.

The phase composition of the samples was identified by X-ray diffraction in an Empyrean diffractometer equipped with a $\mathrm{Cu}$ lamp and a X'Celerator silicon detector. The analyses were carried out in the range from 5 to $60^{\circ} \theta$, and the ICDD PDF-2 database was used to interpret the diffractograms. The phase analysis was then supplemented with a microstructure study performed in the scanning electron microscope Quanta FEG 250, equipped with an X-ray microanalyzer. The microstructure testing was done on powdered, unsputtered samples deposited on the adhesive carbon tape glued to the microscope base. The tests were carried out under low vacuum conditions (pressure $=30 \mathrm{~Pa}$ ) using a $5 \mathrm{kV}$ electron beam.

\section{Results and discussion}

\subsection{Phase analysis}

Figure 2 shows the XRD patterns of the samples. The X-ray analysis of samples A and B shows that they consist mainly of calcite (Fig. 2a, b). The calcium carbonate formed as a result of carbonation of the calcium hydroxide exuding onto the stair side surfaces [6]. This phenomenon can be observed on concrete structure elements, e.g., bridges, viaducts [4], especially when the proper drainage of water has been neglected. The formation of efflorescence does not significantly reduce the durability of the concrete, but only affects the aesthetics of the structure. 


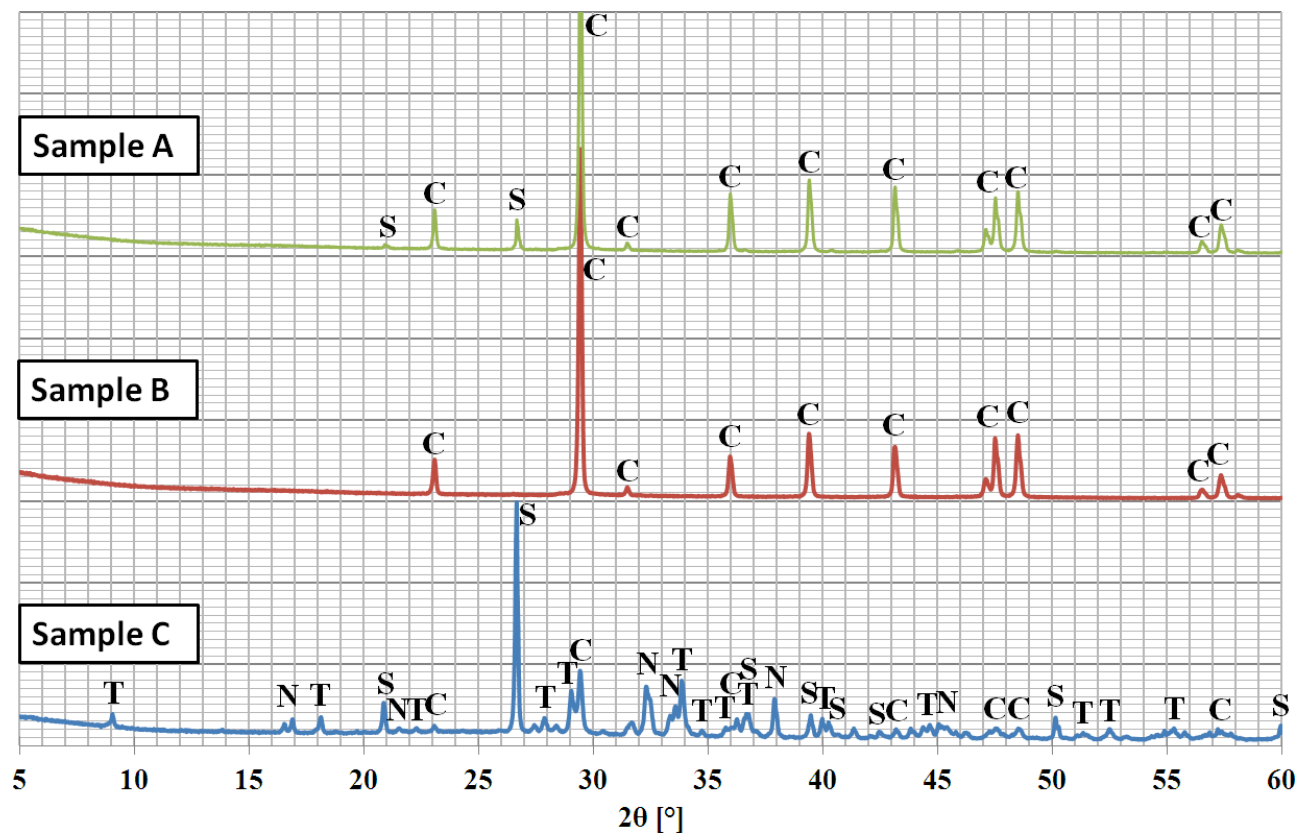

Fig. 2. XRD patterns of samples taken from the stair side surfaces: $\mathrm{C}$ - calcite $\mathrm{S}$ - quartz, $\mathrm{N}$ thermonatrite, $\mathrm{T}-$ trona.

The phase composition of sample C (Fig. 2c) differs greatly from that of samples A and B. The sample $\mathrm{C}$ contains calcite, quartz and hydrated sodium carbonates - trona $\left(\mathrm{Na}_{2} \mathrm{CO}_{3} \cdot \mathrm{NaHCO}_{3} \cdot 2 \mathrm{H}_{2} \mathrm{O}\right)$ and thermonatrite $\left(\mathrm{Na}_{2} \mathrm{CO}_{3} \cdot \mathrm{H}_{2} \mathrm{O}\right)$. Hydrated sodium carbonates may be formed by the carbonation of the alkali-aggregate reaction products. There are two types of alkali-aggregate reactions that pose a risk to concrete: alkali-silica reaction and alkali-carbonate reaction. Trona, a crystalline product, forms when sodium ions are responsible for alkali-silica reaction $[7,8]$. The source of sodium ions was mainly de-icing salt used to remove ice from the surface of the stair. According to Katayama [9], trona could also result from the carbonation of sodium hydroxide exuding onto the concrete surface.

Thermonatrite can form during dedolomization during alkali-carbonate reaction according to the equation (1) [9]:

$$
\mathrm{CaMg}\left(\mathrm{CO}_{3}\right)_{2}+2 \mathrm{NaOH} \stackrel{\mathrm{H}_{2} \mathrm{O}}{\longrightarrow} \mathrm{Mg}(\mathrm{OH})_{2}+\mathrm{CaCO}_{3}+\mathrm{Na}_{2} \mathrm{CO}_{3} \cdot \mathrm{H}_{2} \mathrm{O}
$$

or from sodium carbonate (trona) at a temperature over $57^{\circ} \mathrm{C}[10]$, which may have been present on the south side of the stairs during the summer months. Thermonatrite could also form as a result of the carbonation of sodium hydroxide with silica reaction products [11].

Calcite may have been formed both during the carbonation of portlandite and in the dedolomization process.

In contrast to the samples $\mathrm{A}$ and $\mathrm{B}$, sample $\mathrm{C}$ exhibits a high background on the XRD pattern. 


\subsection{Microstructure}

Microstructural analysis of samples A and B confirms the results of the X-ray phase composition studies. The efflorescences consist of calcium carbonates less or better developed (Fig. 3). The well-formed calcite crystals (Fig 3a) are dominant, as identified from the diffractograms. Spherical agglomerations of metastable vaterite (Fig 3b) occur less frequently. The metastable vaterite, which results from the carbonation of concrete, transforms into calcite over time [12].
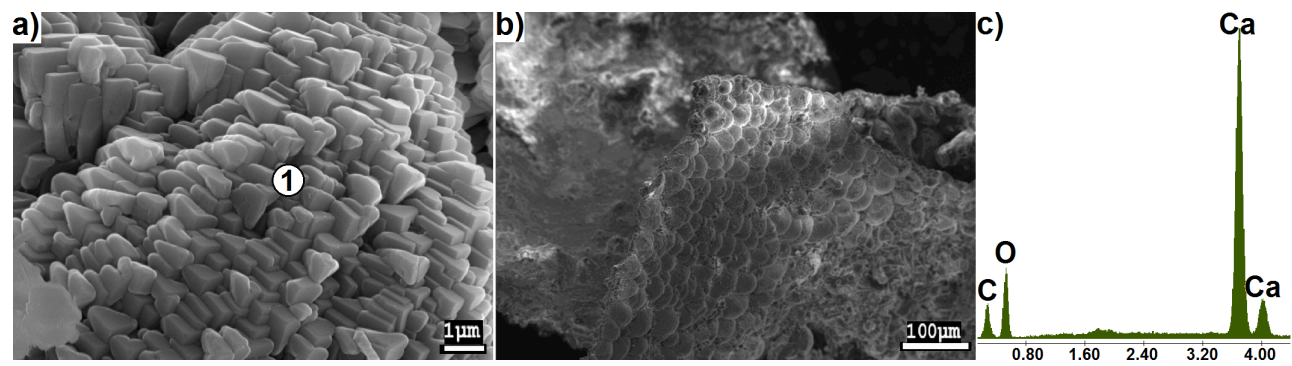

Fig. 3. Microstructure of sample B: a) calcite crystals (mag. $10000 \times$ ); b) spherical agglomeration of vaterite (mag. $3500 \times$ ); c) EDS at point 1 .

Needle- and bar-like crystals are the main components of sample C (Fig. 4a). With high content of sodium and an increased content of carbon (Fig. 4b), they may be the hydrated sodium carbonates identified in the X-ray analysis [13]. The presence of silicon in the samples containing sodium carbonates can be explained by the occurrence of residual uncarbonated silica gel. A significant proportion of potassium is also observed in some of the carbonates (Figs 5b, 5e).

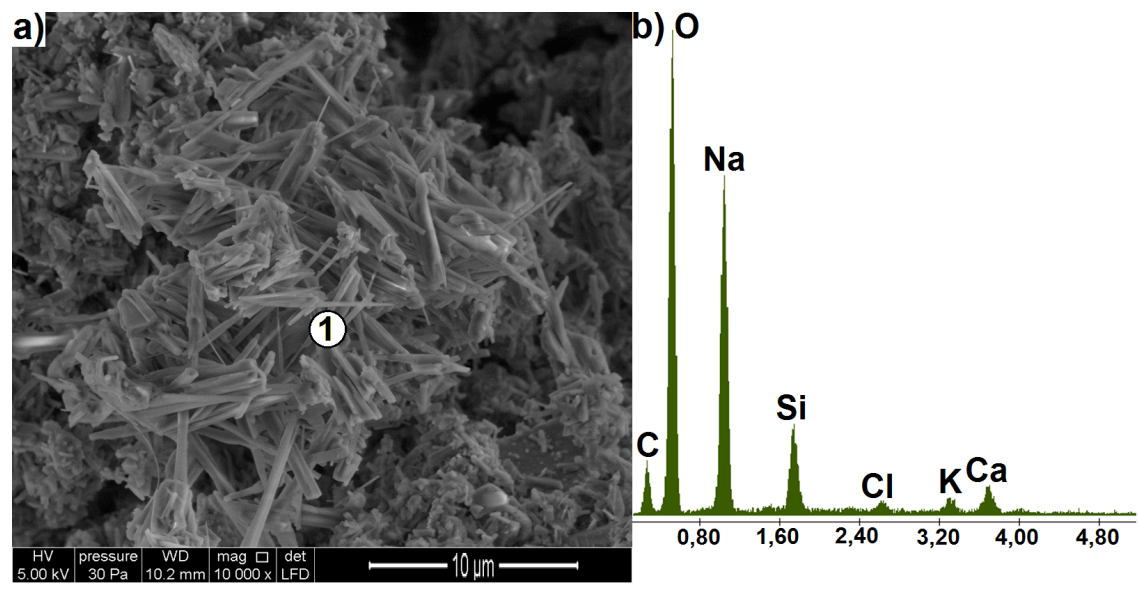

Fig. 4. Microstructure of sample C: a) hydrated sodium carbonates; b) EDS at point 1.

A dense amorphous phase was observed in the corroded concrete fragments (Fig. 4a, c), the presence of which was suggested by a high background exhibited on the XRD pattern. The X-ray microanalysis reveals a significant silicon content typical for the alkaline silica gel formed as a result of the alkali-silica reaction with sodium and potassium $[14,15,16$, 17]. The presence of chlorine and even single crystals of sodium chloride are also detected (Fig. 5f). 


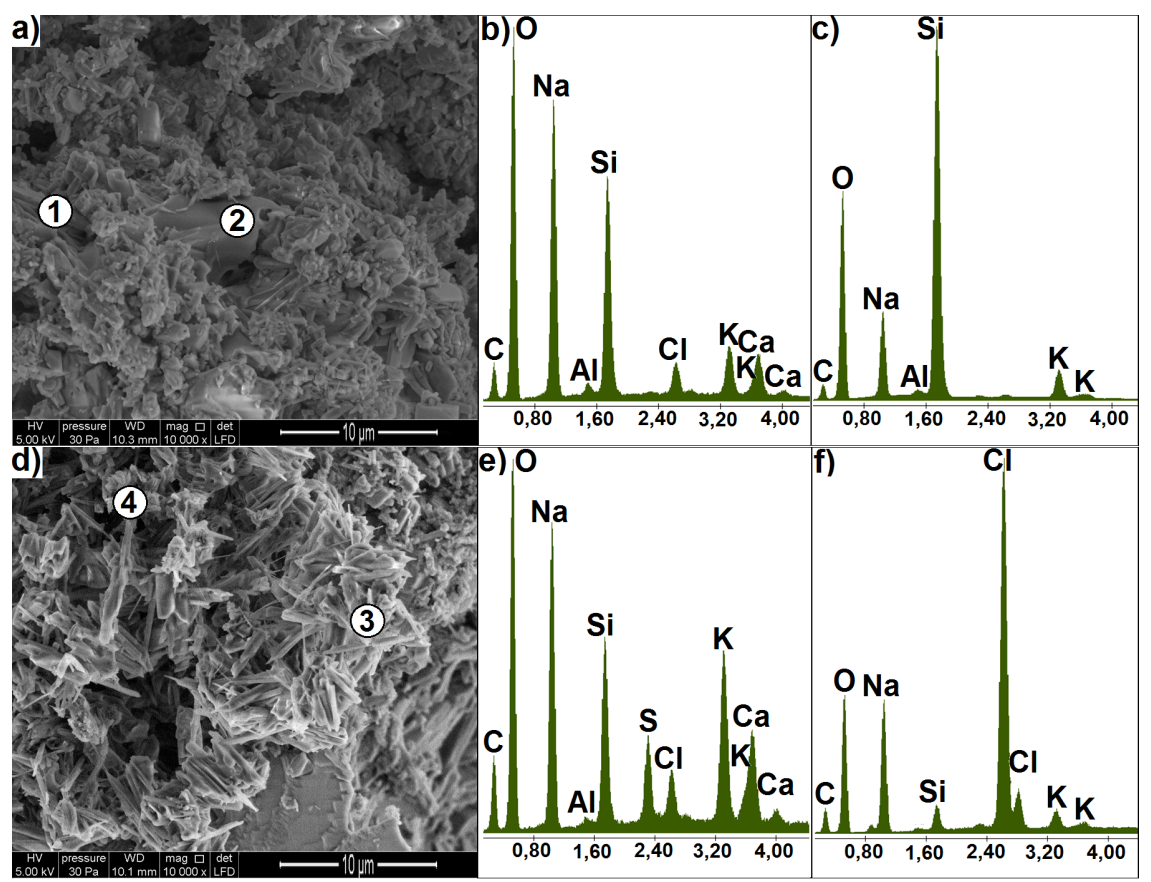

Fig. 5. a), d) Microstructure of sample $C$ with the EDS at points 1 (b), 2 (c), 3 (e) and 4 (f) respectively.

Sample C contains single portlandite crystals coated with hydrated sodium carbonate (Fig. 6). The presence of portlandite may suggest that the calcite detected during the X-ray analysis could be formed partially as a result of the transformation of thermonatrite [9]:

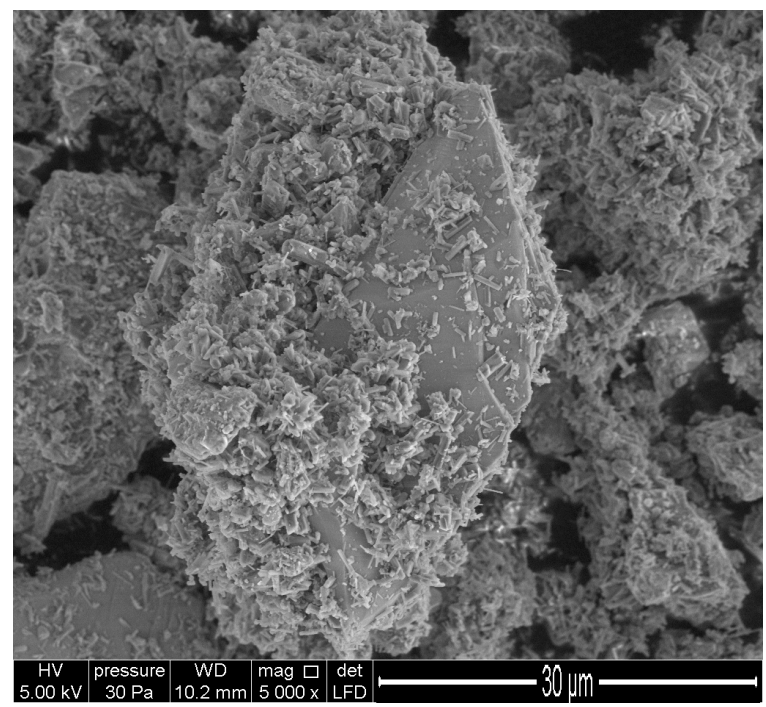

Fig. 6. Crystal of portlandite covered in hydrated sodium carbonates.

$$
\mathrm{Ca}(\mathrm{OH})_{2}+\mathrm{Na}_{2} \mathrm{CO}_{3} \cdot \mathrm{H}_{2} \mathrm{O} \stackrel{\mathrm{H}_{2} \mathrm{O}}{\longrightarrow} \mathrm{CaCO}_{3}+2 \mathrm{NaOH}+\mathrm{H}_{2} \mathrm{O}
$$




\section{Summary}

As it results from the data presented above, the encrustations and surface scaling on the surface of the stairs is the consequence of calcium hydroxide washing out and subsequent formation alkali-aggregate reaction products. Calcium hydroxide and alkali-aggregate reaction products transported to the surface of concrete are subjected to the carbonation process, resulting in the formation of calcite, trona and thermonatrite. These phases constitute the "building material" of encrustations and scaling present on the concrete surface.

The X-ray analysis revealed the presence of hydrated sodium carbonates, formed both during the carbonation of sodium hydroxide and alkali-silica reaction products. The amorphous, compact silicate gel of sodium silicate observed as a part of the SEM image suggests the occurrence of alkali-silica reaction [2]. The study of cores taken from the stairs allowed determining the contribution of particular types of alkali-aggregate reactions in the processes of concrete corrosion.

The reaction products of alkali-aggregate are rich in sodium. The X-ray microanalysis indicated the presence of chlorine and even sodium chloride crystals in the samples. Thus, the sodium ions derived from sodium chloride can promote the alkali-aggregate reaction. The source of sodium chloride is the de-icing salt used to remove ice from the stairs [18]. The granite tiles used on the surface of the stairs are made of granite of high water absorption, and the simultaneous lack of insulating layers on the surface of the concrete stairs causes the migration of de-icing salt solutions into the concrete. Calcium hydroxide, sodium hydroxide and hydrated sodium silicates emerge on the side surfaces of the stairs. Carbonation of these products on the side surfaces of the concrete stairs produces hydrated sodium carbonates, whose presence was confirmed in the study.

The occurrence of the alkali-aggregate reaction could be prevented by using mineral additives or chemical admixtures during the production of concrete $[1,14,19,20,21]$. They would increase the tightness of concrete and counteract the alkali-aggregate reaction by binding the sodium and potassium ions in the C-S-H phase [1]. The use of a binder with mineral additives can also counteract the leaching. In the pozzolan reaction relatively easily soluble calcium hydroxide can be replaced by the C-S-H phase.

As a result of this observed corrosion processes the concrete structure becomes loosened and weakened to such an extent that the granite tiles can fall off the stairs.

\section{References}

1. W. Kurdowski, Chemia Cementu i Betonu (Kraków 2010)

2. M.D.A. Thomas, B. Fournier, K.J. Folliard, Y.A. Resendez, Report No. FHWA-HIF12-022 (2011)

3. Z. Owsiak, J. Zapała-Sławeta, P. Czapik, Bull. Pol. Ac.: Tech. 63, 23-30 (2015)

4. W. Piasta, Eng. Fail. Anal. 79, 606-614 (2017)

5. M.D.A. Thomas, B. Fournier, K.J. Folliard, Report No. FHWA-HIF-13-019 (2013)

6. W. Grzmil, Z. Owsiak, Cement Wapno Beton 18, 137-144 (2013)

7. C. Balachandran, J.F. Muñoz, T. Arnold, Cem. Con. Res. 92, 66-74 (2017)

8. C.E. Tambelli, J.F. Schneider, N.P. Hasparyk, P.J.M. Monteiro, J. Non-Cryst. Solids 352, 3429-3436 (2006)

9. T. Katayama, Mater. Charact. 53, 85-104 (2004)

10. K.J. Cho, T.C. Keener, S.-J. Khang, Powder technol. 184, 58-63 (2008) 
11. L. Baingam, T. Nawa, E. Iwatsuki, T. Awamura, Constr. Build. Mater. 95, 820-831 (2015)

12. S. Liu, Z. Dou, S. Zhang, H. Zhang H., X. Guan, C. Feng J. Zhang, Constr. Build. Mater 150, 591-594 (2017)

13. R.S. Gärtner, G.-J. Witkamp, Hydrometallurgy 88, $75-91$ (2007)

14. J. Zapała-Sławeta, Z. Owsiak, Bull. Pol. Ac.: Tech 65, 773-778 (2017)

15. P. Czapik, Z. Owsiak, Cement Wapno Beton 21, 79-85 (2016)

16. Z. Owsiak, J. Zapała-Sławeta, Ceramics - Silikáty 57, 138-145 (2013)

17. Z. Owsiak, Ceramics - Silikáty 47, 108-115 (2003)

18. A. Shayan, A. Xu, G. Chirgwin, H. Morris, Cem. Concr. Res. 40, 563-568 (2010)

19. Z. Owsiak, J. Zapała-Sławeta, Cement Wapno Beton 20, 25-31 (2015)

20. Z. Owsiak, P. Czapik, Cement Wapno Beton 19, 152-157 (2014)

21. Z. Owsiak, P. Czapik, Cement Wapno Beton 18, 310-320 (2013) 
